\title{
SANTA AFRO CATARINA: ACERVO DIGITAL E EDUCAÇÃO PATRIMONIAL
}

\section{SANTA AFRO CATARINA: DIGITAL COLLECTION AND HERITAGE EDUCATION}

\author{
Andréa Ferreira Delgado* \\ Beatriz Gallotti Mamigonian**
}

\begin{abstract}
Resumo: A reflexão sobre a constituição de um acervo de documentos acerca da presença de africanos e afrodescendentes na Ilha de Santa Catarina para o website "Santa Afro Catarina" é o foco desse artigo. No Programa Santa Afro Catarina, o trabalho com documentos históricos no ofício do historiador e na produção do conhecimento histórico escolar foi articulado a uma proposta de Educação Patrimonial. Composta por um conjunto de projetos que procuram ressignificar o espaço urbano e propor novas abordagens para o ensino da História local e o turismo cultural, a proposta se baseia em tramas históricas constituídas por pesquisa, que dão visibilidade ao protagonismo de homens e mulheres, escravos e libertos de origem africana, numa gama de experiências individuais e coletivas.
\end{abstract}

Palavras-chave: Acervo digital. Diáspora africana. Educação patrimonial. Ensino de história. Espaço urbano.

\footnotetext{
** Professora no Departamento de Metodologia do Ensino da Universidade Federal de Santa Catarina (UFSC) e no Programa de Mestrado Profissional em Ensino de História (PROFHISTÓRIA). E-mail: andreadelgado@uol.com.br

** Professora no Departamento de História da Universidade Federal de Santa Catarina (UFSC) e no Programa de Pós-Graduação em História da mesma universidade.

E-mail: beatriz.mamigonian@ufsc.br
} 


\begin{abstract}
This article addresses the constitution of the collection of documents on the African presence on the Island of Santa Catarina that is the basis of the "Santa Afro Catarina" website. In the Santa Afro Catarina outreach program, the use of historical documents in the historian's craft and in the education environment were combined to a heritage education initiative. This initiative is composed by a series of projects that give new meanings to urban spaces and propose new approaches for teaching local history and for addressing cultural tourism. It consists of disseminating new narratives based on historical research, which give agency to men and women of African descent, enslaved or freed, in different individual and collective experiences.
\end{abstract}

Keywords: Digital collection. African diaspora. Urban space. Heritage education. History teaching.

\title{
INTEGRAÇÃO ENTRE ENSINO, PESQUISA E EXTENSÃO
}

O Programa Santa Afro Catarina foi criado com o duplo desafio de articular a pesquisa histórica ao ensino de História e de estabelecer interlocução para além dos muros da Universidade. A constituição de um acervo digital de documentos é o eixo do conjunto de projetos que compõem o Programa. Constituído por documentos textuais e iconográficos selecionados em arquivos e bibliotecas e contextualizados à luz da historiografia sobre a presença africana nas Américas, o acervo de referências às experiências históricas de africanos e afrodescendentes em Santa Catarina possibilita, por meio do exercício do ofício do historiador, a constituição de tramas históricas; também proporciona a inserção das operações do procedimento histórico nas salas de aula da educação básica e é ainda utilizado em diferentes ações educativas relacionadas ao patrimônio cultural. ${ }^{1}$

O Programa, iniciativa das professoras Andréa Delgado e Beatriz Mamigonian, iniciou em 2011, com a oferta de disciplinas no curso de História da Universidade Federal de Santa Catarina. A formação concomitante de historiadores e de professores, objetivo do Projeto Pedagógico do curso de História da UFSC, se dá através de três núcleos - Núcleo de Conteúdos Específicos, Núcleo dos Conteúdos Pedagógicos e o Núcleo da Prática Profissional. ${ }^{2}$ A inovação do Programa Santa Afro Catarina é articular disciplinas dos três núcleos em torno da construção de uma proposta de educação patrimonial que visa promover a identificação, a valorização e a difusão do patrimônio cultural relacionado à história e à memória dos africanos e afrodescendentes em Santa Catarina.

Assim, em 2011 e 2012, nas disciplinas de "Laboratório de Ensino de História Social do Trabalho e da Cultura" e nas de "Estágio Supervisionado em História I, II e III", sob orientação das professoras coordenadoras, os alunos e alunas elaboraram narrativas históricas temáticas, materiais didáticos e projetos 
de educação patrimonial associados a esses objetivos. Desde então, dezenas de alunos de graduação (sobretudo de História, mas também de Letras, Artes Cênicas, Design e Computação) receberam bolsas para atuar no "Programa Santa Afro Catarina". ${ }^{3}$ Com isso, quer seja cursando disciplinas ou participando de atividades extracurriculares, os estudantes são desafiados a se tornarem autores e protagonistas de práticas que associam a produção do conhecimento histórico ao ensino de História e a projetos de Educação Patrimonial, dirigida aos alunos da Educação Básica, aos moradores de Florianópolis e aos turistas.

Os turistas que circulam pelo centro de Florianópolis ou visitam as antigas freguesias, hoje bairros conhecidos pelas praias e restaurantes de frutos do mar, têm poucos indícios da forte presença africana entre os colonizadores. Embora nas últimas décadas uma significativa produção historiográfica permita vislumbrar homens e mulheres africanos e afrodescendentes numa gama de atividades e de espaços sociais desde o período colonial, esses sujeitos históricos estão ainda em grande parte ausentes também da história local trabalhada nas escolas ou ainda são tratados apenas na condição de mão-de-obra, sem que seu protagonismo social seja devidamente valorizado, nem durante a vigência da escravidão e muito menos posteriormente.

Quer seja no campo do patrimônio, do turismo ou da educação escolar, os discursos que divulgam o patrimônio cultural fundamentam-se nos bens materiais e nas práticas culturais de origem lusitana. ${ }^{4}$ Torna-se, portanto, necessário que a pesquisa histórica produzida sobre a diáspora africana em Santa Catarina colabore para questionar essa identidade hegêmonica.

As relações estabelecidas com os vestígios do passado e a produção do discurso histórico foram profundamente abaladas pelo surgimento e agenciamento da internet na constituição de um conjunto de práticas culturais que configuram a sociedade contemporânea. Os relacionamentos, a comunicação, o consumo, a construção e a divulgação do conhecimento são temas exemplares para a reflexão acerca da onipresença da web no nosso cotidiano.

A interação com o conhecimento histórico vem se transformando na era digital. ${ }^{5} \mathrm{O}$ tema da diáspora africana nas Américas, cuja historiografia está sendo renovada nas últimas décadas a partir de um frutífero debate entre americanistas e africanistas, se beneficiou enormemente da divulgação de acervos e bancos de dados na web. Um dos portais mais acessados sobre essa temática, o "Transatlantic Slave Trade Voyages", por exemplo, é resultado de um esforço coletivo que atualizou o trabalho realizado na década de 1960 pelo historiador norte-americano Philip Curtin para estimar o volume, as flutuações e a distribuição na África e nas Américas do comércio transatlântico de escravos. O banco de dados online hoje contém quase 35 mil travessias do período entre os séculos XVI e XIX, e dados como nomes de proprietários, de mestres das embarcações, capacidade dos navios, tempo de travessia, 
número de homens, mulheres e crianças a bordo e ocorrências como revoltas escravas. ${ }^{6}$ Um desdobramento do projeto, o "African Origins", lista $91 \mathrm{mil}$ nomes de africanos e africanas que foram emancipados de navios negreiros durante a repressão ao tráfico de escravos no século XIX, com o objetivo de identificar, a partir de seus prenomes, suas origens na África. ${ }^{7}$ Um outro acervo importante relativo à presença africana nas Américas é aquele reunido no portal "Ecclesiastical and Secular Sources for Slave Societies", sediado pela universidade norte-americana de Vanderbilt. Disponibilizando quase 300 mil imagens de documentos do Brasil, de Cuba, da Colômbia e da Flórida no período espanhol, o projeto oferece material bruto de pesquisa para várias temáticas associadas à presença africana em regiões hispânicas nas Américas, mais notadamente registros eclesiásticos, resgatados muitas vezes de arquivos ameaçados. ${ }^{8}$ Outro acervo digital que tem contribuído enormemente para a pesquisa e o ensino na área da diáspora africana nas Américas é o do portal "The Atlantic Slave Trade and Slave Life in the Americas: A Visual Record", baseado na Universidade da Virgínia. ${ }^{9} \mathrm{O}$ acervo disponibiliza mais de 1200 imagens relativas ao tráfico transatlântico e à escravidão nas Américas, sendo que cada imagem recebeu um verbete com a atribuição de fonte e comentários de especialistas. Muitos desses documentos são mapas de diferentes regiões da África e das Américas, de diversas origens e momentos históricos, o que permite trabalhar em comparação a colonização britânica, francesa, espanhola, holandesa e portuguesa.

Dois acervos brasileiros merecem destaque, dentre vários. A Base de Dados "Legislação: Trabalhadores e Trabalho em Portugal, Brasil e África Colonial Portuguesa", desenvolvida no Centro de Pesquisa em História Social da Cultura (CECULT) da Unicamp, reúne texto integral da legislação portuguesa e brasileira acerca de trabalho escravo e livre no Brasil, em Portugal e nas colônias portuguesas na África entre os séculos XVI e XX. ${ }^{10}$ Dentre vários outros acervos resultantes dos projetos desenvolvidos no CECULT, referência na área de história social da escravidão, do trabalho e do direito no Brasil, destaca-se o de "Mapas Temáticos". ${ }^{11}$ Já o acervo do Laboratório de História Oral e Imagem (LABHOI) da Universidade Federal Fluminense é bastante eclético e decorre de coleta feita durante diversos projetos de pesquisa dos professores integrantes do Laboratório. De interesse particular é a seção "Memória, África, Escravidão", que contém entrevistas gravadas, vídeos e registros fotográficos, além de documentários produzidos a partir da pesquisa, como os da série "Passados Presentes". ${ }^{12}$

Todos os projetos citados têm em comum o esforço de seleção e a preocupação com a difusão de documentos históricos antes dispersos ou inacessíveis ao público geral. Os projetos lidam de forma diferente, no entanto, com o público escolar. O único deles que oferece material didático e sugestões para o uso do conteúdo do website em sala de aula no ensino primário e secundário é o "Transatlantic Slave Trade Voyages". ${ }^{13}$ 
O esforço de conceitualização dos acervos, de exposição lógica do conteúdo nos portais citados e ainda a preocupação de diálogo com as temáticas da área foram norteadores da formulação do website Santa Afro Catarina. Mas para além da reunião e organização de um acervo digital, houve grande investimento em interpretação e formas de apresentação diferenciadas. Além de problematizar as "novas modalidades de construção, publicação e recepção dos discursos históricos"14 na era digital, nos preocupou a formulação de estratégias de apropriação da internet que promovessem a associação entre a compreensão do passado e as vivências e ações dos homens e mulheres no mundo em que vivem.

Diversas inquietações nos moveram a elaborar o conjunto de projetos que compõem o website Santa Afro Catarina: Como criar um acervo digital de documentos históricos e associá-lo, concomitantemente, à pesquisa histórica e ao ensino de História? Quais os caminhos para utilizar um acervo de documentos garimpados de diferentes arquivos durante pesquisas acadêmicas para a construção de narrativas históricas que sejam significativas para um público diversificado? Quais metodologias de ensino-aprendizagem sugerir para estimular que o acervo digital seja utilizado para a construção do conhecimento histórico escolar? Como associar a pesquisa histórica ao campo do patrimônio de forma a propor o inventário de lugares da memória ${ }^{15}$ dos africanos e afrodescendentes na Ilha de Santa Catarina? Quais as estratégias para produção de instrumentos de educação patrimonial capazes de propor novas leituras e apropriações do espaço na Ilha de Santa Catarina?

Delineamos itinerários diversos, mas interligados entre si, que possibilitam proposições para mobilizar essas questões na construção de propostas de intervenção social e de formação de historiadores e professores. Essa trajetória resultou na estruturação do website "Santa Afro Catarina" nas seções "Temas", "Acervo", "Espaço", "Tempo", "Roteiros" e "Na Escola", organizadas de modo a estimular diferentes percursos de leitura e de pesquisa, configurando apropriações diversas do conteúdo disponível.

\section{ACERVO DIGITAL E A CONSTITUIÇÃO DAS NARRATIVAS TEMÁTICAS}

Para a elaboração dos "Temas" que entrelaçam as experiências sociais de homens e mulheres africanos e afrodescendentes aos marcos urbanos da Ilha de Santa Catarina, mobilizamos o acervo de documentos do Laboratório de História Social do Trabalho e da Cultura da $\mathrm{UFSC}^{16}$ e realizamos uma minuciosa pesquisa bibliográfica da produção historiográfica acerca da escravidão e do pós-abolição em Santa Catarina.

Em dois semestres da disciplina "Laboratório de Ensino de História Social do Trabalho e da Cultura" foram produzidas as oito narrativas temáticas 
que compõem o website "Santa Afro Catarina" - "Viver de Quitandas", "Devoção ao Rosário e Festas de Africanos na Ilha"; "A Desterro de Cruz e Sousa"; "Armação baleeira da Lagoinha e engenhos do Ribeirão da Ilha"; "Porto antes do Miramar"; "A Lagoa também é dos pretos"; "Reformas urbanas no pós-Abolição", “Armação da Piedade e engenhos em São Miguel”.

Diferentes lugares do centro da cidade de Florianópolis, dos distritos da Armação do Pântano do Sul, do Ribeirão da Ilha e da Lagoa da Conceição, além do município de Governador Celso Ramos ${ }^{17}$ emergem dessas narrativas ressignificados pela pesquisa histórica.

As tramas das narrativas temáticas operam o "jogo de escalas" da microhistória, que permite abordar processos históricos mais amplos por meio da investigação de trajetórias individuais e coletivas. ${ }^{18}$ Os africanos e afrodescendentes são, assim, considerados protagonistas da história de Santa Catarina, visto que não se trata de acrescentar "contribuições" desses sujeitos, mas sim de reescrever a trama das relações sociais de determinados lugares a partir das trajetórias desses homens e mulheres, com suas estratégias de vida e ações individuais e coletivas, tal como proposto por Beatriz Mamigonian e Joseane Zimmermann Vidal. ${ }^{19}$

Nesse exercício de delimitar uma temática, elaborar questões, ler a bibliografia, selecionar documentos disponíveis em acervos, pesquisar novos documentos, cotejar documentos e produções historiográficas e elaborar uma narrativa, os historiadores em formação têm a oportunidade de desenvolver as habilidades e competências do seu ofício.

$\mathrm{Na}$ maior parte das vezes, eles não percorreram os arquivos, visto que os documentos já constituíam acervos construídos por meio de outras pesquisas. Mas nem por isso deixaram de sentir e se surpreender pelo "sabor do arquivo", tão bem descrito e problematizado por Arlette Farge por meio de suas experiências de pesquisa nos arquivos judiciários:

O arquivo é uma brecha no tecido dos dias, a visão retraída de um fato inesperado. Nele tudo se focaliza em alguns instantes de vida de personagens comuns, raramente visitados pela história, a não ser que um dia decidam se unir em massa e construir aquilo que mais tarde se chamará de história. O arquivo não escreve páginas de história. Descreve com as palavras do dia a dia, e no mesmo tom, o irrisório e o trágico, onde o importante para a administração é saber quem são os responsáveis e como puni-los. Perguntas e perguntas se sucedem; cada queixa, cada auto é uma cena na qual se diz aquilo que normalmente não vale a pena ser dito. E muito menos escrito; os pobres não escrevem, ou muito pouco, sua biografia. ${ }^{20}$ 
A historiadora descreve com maestria o longo e árduo trabalho nos arquivos, o fascínio diante das descobertas - "nasce assim o sentimento ingênuo, porém profundo, de romper um véu, de atravessar a opacidade do saber e de chegar, como depois de uma longa viagem incerta, ao essencial do seres e das coisas" 21 , a tensão entre a "paixão" e o desejo de oferecer o documento inteiro à leitura e a "razão" que determina o questionamento das fontes e sua análise pelas operações do procedimento histórico para que possam adquirir sentido.

Farge alerta para as "armadilhas e tentações" da predileção pelos arquivos, quando o historiador, "pelo prazer de ser surpreendido, pela beleza dos textos e o excesso de vida ofertado em linhas ordinárias" ${ }^{22}$, precisa fugir à tentação de identificar-se com os personagens, as situações ou maneiras de ser encontradas nos textos e manter a "vigilância" configurada na barreira com a ausência da distância, no abandono da crença que o documento se basta a si mesmo e na adoção de procedimentos de interrogação e de questionamento constante dos documentos. Assim, diante da "emergência de vidas" encontrada nos arquivos, o historiador produz, por meio da "construção plausível e verossímil de continuidades e descontinuidades do passado, a partir de exigências científicas", uma narrativa histórica "que busca estar à altura dessa irrupção e desse peso, ou seja, que leva em conta esses retalhos de realidades exibidas, que desvenda estratégias individuais e sociais para além dos não ditos e dos silêncios, coloca-os em ordem, e depois propõe uma inteligibilidade própria sobre a qual é possível refletir". ${ }^{23}$

Sensações semelhantes a essas do historiador em trabalho de campo poderiam sentir aqueles que buscam ou são surpreendidos pelos documentos que compõem os acervos digitais? Diante dos documentos disponíveis nos acervos digitais, o internauta se sentirá motivado a refazer o caminho da pesquisa do historiador ou será instigado a traçar seus próprios percursos para interrogar e interpretar as fontes?

Indagações como essas acompanharam o processo de seleção de documentos, digitalização e organização do acervo do website "Santa Afro Catarina", composto por um conjunto de documentos manuscritos, iconográficos, materiais, cartográficos, audiovisuais e orais, que incorporam fontes coletadas durante pesquisas realizadas para projetos anteriores e, ao mesmo tempo, resultam da coleta e digitalização de documentos encontrados em diversos arquivos e conjuntos documentais durante o processo de elaboração das narrativas temáticas. A organização dos documentos da seção "Acervo" segue sua tipologia: "Manuscritos", "Impressos", "Imagens", "Objetos", "Mapas", "Entrevistas" e "Vídeos", incluindo também textos-síntese sobre "Pessoas", "Lugares" e "Eventos". Ressalta-se que os filtros de busca permitem diversos caminhos para a pesquisa.

No texto dos "Temas" utiliza-se o recurso do link para acesso aos documentos primários e aos pequenos textos acerca pessoas, lugares e eventos 
citados. Dentre estes, destacamos pequenas narrativas biográficas de homens e mulheres, escravos e libertos, que foram elaboradas a partir da combinação de episódios descobertos em documentos diversos que permitem vislumbrar e registrar momentos significativos da trajetória de vida desses sujeitos e que também representam experiências da diáspora africana. Tal como no exemplo de "Maria Mina":

No ano de 1867 , o vão da coluna $n^{\circ} 5$ do Mercado de Desterro era ocupado por Maria Mina e por Thereza, cuja origem desconhecemos. Sabemos que Maria Mina já era liberta, pois fez o registro de sua alforria em cartório em 31 de julho de 1860, diante de Luis de Santa Anna Carpes, seu proprietário, para o qual pagou a quantia de 800 mil réis por sua liberdade, dinheiro obtido através de uma terceira pessoa. Pode-se encontrar essa africana, que no Brasil foi chamada de Maria, nos livros da Câmara pagando imposto para vender legalmente quitandas pelas ruas, assim como faziam outras mulheres e homens, escravos ou libertos, crioulos ou africanos, que eram presença marcante no comércio de alimentos nas ruas de Desterro. A quitandeira Maria Mina mantinha bons relacionamentos com pessoas influentes de Desterro. Com Clemente Gonçalves, presidente da Câmara Municipal na época da inauguração do Mercado, ela conseguiu um adiantamento para pagar sua alforria. Com o Coronel Feliciano Alves de Brito, em 1883, fez um contrato para libertar o pardo Manoel, que ela dizia ser seu sobrinho. Após um ano, o Coronel, que não recebera seu pagamento, desconfiou de que Maria havia empregado Manoel no serviço marítimo e o fazia pagar-lhe 'jornais'. Não sabemos os laços que ligavam Maria e Manoel ou se a quitandeira adquirira o rapaz para torná-lo seu cativo, assim como fizeram muitos outros libertos. Sabemos apenas que Maria Mina negociava com homens importantes de Desterro e que eles reconheciam sua capacidade de gerar recursos a partir do tabuleiro, pois lhe emprestaram somas altas de dinheiro. ${ }^{24}$

Essa narrativa sobre Maria Mina pode ser acessada por meio de um link presente na narrativa "Viver de Quitandas" ou ainda por meio do ícone "Pessoas", disponível no "Acervo". Está também relacionado ao "Lugar" do primeiro Mercado Público de Desterro. Dessa forma, cada informação tem possibilidades diversas de leituras. No contexto da narrativa temática que aborda o abastecimento e a produção de gêneros alimentícios, associando a paisagem urbana de Desterro às outras freguesias da Ilha de Santa Catarina, Maria Mina é uma das quitandeiras que percorre o Porto, a antiga Praça do 
Mercado, as ruas de Desterro. Essa trajetória coletiva é singularizada pelos episódios descritos nos documentos e permite questionar a historiografia tradicional sobre a escravidão ao ressaltar o protagonismo de uma mulher africana que consegue comprar sua liberdade, vender seus produtos no Mercado de Desterro, estabelecer negociações e contratos com pessoas influentes e adquirir um escravo. Talvez o internauta que acesse a biografia de Maria Mina pelo "Acervo" faça outras conexões e estabeleça distintas relações a partir das questões que motivam sua pesquisa.

\section{ACERVO DIGITAL E EDUCAÇÃO PATRIMONIAL}

Os regimes discursivos que patrimonializaram determinados lugares, personagens e narrativas no processo de construção da memória local e regional, promovendo a invisibilidade da história e da cultura afrobrasileira em Santa Catarina ${ }^{25}$, devem ser questionados no processo de incorporação do patrimônio como objeto de pesquisa e de intervenção do historiador e do professor de História. A Educação Patrimonial, ou seja, o desenvolvimento de ações educativas associadas aos bens culturais precisa compreender a investigação acerca das políticas públicas de produção de determinado passado e memória pela ação de agentes, instituições e instrumentos próprios do campo do patrimônio.

Ao historicizar a ação do Instituto do Patrimônio Histórico e Artístico Nacional (IPHAN), órgão federal responsável pela institucionalização de um conjunto de práticas culturais que sacramentou determinados bens culturais como representativos da história e da identidade nacional, observa-se que a constituição do patrimônio nacional alijou e silenciou os marcos da presença dos africanos e afrodescendentes, assim como a dos indígenas, ao compor um mapa de bens tombados que representavam a elite política, católica e branca, tal demonstrou Silvana Rubino ao inventariar os bens tombados pelo IPHAN. ${ }^{26}$

Somente a partir da ampliação do conceito de patrimônio, nos anos 1970 e 1980, com a introdução da concepção de patrimônio cultural e da incorporação da noção de cidadania cultural ao campo do patrimônio, tal como registrado nos artigos referentes ao patrimônio na Constituição de 1988, estabelecem-se as condições para a inclusão de bens relacionados à história e à cultura afrobrasileira no universo do patrimônio - como ocorreu com o tombamento, em 1982, do Terreiro da Casa Branca, em Salvador, e da Serra da Barriga, em União dos Palmares, Alagoas.

Outro marco desse processo, é o Decreto 3.551, de 4 de agosto de 2000, que criou o "Programa Nacional do Patrimônio Imaterial", lançado em 2004, responsável por identificar, registrar, salvaguardar e promover a dimensão imaterial do patrimônio cultural. Significativamente o primeiro bem 
a receber, em 2002, o registro no "Livro dos Saberes" e o título de "Patrimônio Cultural do Brasil" foi um bem indígena, a arte kusiwa, pintura corporal e arte gráfica wajãpi, do Amapá. Entre os Bens Culturais registrados pelo IPHAN, destacam-se vários associados às manifestações culturais afrobrasileiras: Jongo no Sudeste, Tambor de Crioula no Maranhão, Roda de Capoeira, entre outros.

A pesquisa histórica tem muito a contribuir nesse movimento de valorização e visibilização da memória e da cultura afro-brasileira, na proposições de ações de educação patromonial que insiram os vestígios deixados pela ações desses sujeitos históricos num movimento de questionamento do conjunto do campo do patrimônio. Por isso, nossa proposição de educação patrimonial agencia o espaço da Ilha de Santa Catarina para ressignificá-lo.

A partir de cada um dos "Temas" do website foi elaborado um "Roteiro Histórico", que configura determinado itinerário para percorrer lugares do centro de Florianópolis e dos bairros do interior da Ilha que são significativos para a história e a memória dos africanos e seus descendentes. Esses "Roteiros" estão disponíveis em diferentes formatos no website: por meio de um folder, que apresenta um mapa histórico da cidade, onde são sinalizados os pontos do percurso, acompanhados de uma breve descrição, e também marcados na plataforma do Google Maps para localizar no mapa atual de Florianópolis os itinerários do Roteiro, possibilitando que, ao clicar cada um dos pontos, o internauta tenha acesso à mesma descrição presente no folder. Esses lugares são, assim, transformados em cenários da trama histórica, muitas vezes pelo recurso da citação de fontes históricas do "Acervo".

Desde o segundo semestre de 2011, quatro desses "Roteiros Históricos" são ofertados para o público, de forma alternada, no primeiro sábado de cada mês, partindo da Praça XV de Novembro, no centro de Florianópolis. Também são oferecidos, desde 2012, para grupos de estudantes de escolas da educação básica e universitários, mediante o agendamento realizado por professores. Os bolsistas-condutores são os principais protagonistas dos Roteiros, pois orientam os percursos pelo centro de Florianópolis - nos Roteiros "Viver de Quitandas", "Devoção ao Rosário e Festas de Africanos na Ilha" e "A Desterro de Cruz e Sousa" - e pelo Sul da Ilha - durante o Roteiro "Armação baleeira da Lagoinha e engenhos do Ribeirão da Ilha" - utilizando-se do respectivo folder e também de documentos históricos escritos e icnográficos, que são reproduzidos e expostos aos participantes em determinados pontos dos itinerários.

Compreendemos que esses Roteiros Históricos configuram uma prática de educação patrimonial ao agenciar a pesquisa histórica para propor experiências de caráter educativo para moradores e turistas que, ao percorrer a cidade, podem apreender os espaços urbanos a partir vivências prazerosas associadas ao conhecimento histórico. Diferente da visão tradicional do patrimônio presente em guias turísticos ou visitas guiadas ainda correntes no Brasil, a ideia é proporcionar um tratamento diferenciado para o Turismo 
Cultural, modalidade que associa a prática turística a atrativos culturais e, mais especificamente, ao patrimônio histórico e cultural. ${ }^{27}$

Apreensões do espaço urbano em suas múltiplas temporalidades e a interpretação acerca de determinados grupos sociais podem estar conectadas pela abordagem dos bens materiais e imateriais, tal como propõe José Newton Coelho Meneses, por meio do método interpretativo, que objetive:

$1^{\circ}$ ) investigar/apreender; $2^{\circ}$ ) documentar/interpretar; $3^{\circ}$ ) intervir/preservar e $4^{\circ}$ ) informar/difundir o patrimônio histórico, artístico e cultural de um determinado local e, a partir disso, transformá-lo em atrativo a ser reconhecido pela comunidade local, conhecido e compreendido por pessoas que a visitam e, ainda, valorizado e preservado por ambas. ${ }^{28}$

Os Roteiros Históricos do "Programa Santa Afro Catarina", ao privilegiar o espaço como estruturador das narrativas históricas e enfatizar temas caros à historiografia da diáspora africana, ressignificam bairros, ruas, casarios, praças, edifícios religiosos, administrativos e comerciais por meio de tramas históricas que dão visibilidade ao protagonismo de homens e mulheres africanos e seus descendentes. A cidade que emerge dos arquivos foi moldada pelas práticas sociais desses atores, que muitas vezes se opuseram e resistiram às políticas públicas de controle e intervenção, propondo usos diferenciados para os espaços da cidade. Pretendemos, assim, reinterpretar a constituição e as transformações do espaço na Ilha de Santa Catarina.

Em cada um dos Roteiros, os discursos que associam as vivências dos afodescendentes aos marcos urbanos visam atribuir novos significados a prédios e conjuntos históricos tombados - como é o caso da Casa de Câmara e Cadeia; visibilizar bens ainda não consagrados ou ainda evocar os lugares da cidade associados à história e à cultura dos afrodescendentes cujos vestígios foram apagados da malha urbana atual - por exemplo, o Porto, o primeiro Mercado Público, o Rio da Bulha e o casario próximo à Ponte do Vinagre.

Evidencia-se, assim, a pluralidade de interpretações, questionando as matrizes discursivas do campo do patrimônio e do turismo que evidenciam os vestígios da açorianidade na construção da identidade da Ilha de Santa Catarina. Almejamos, com isso, que os Roteiros possam proporcionar novos modos de percepção e de relacionamento com o passado configurado no espaço urbano.

\section{ACERVO DIGITAL E ENSINO DE HISTÓRIA}

Novos desafios foram impostos para a formação de professores desde a promulgação da Lei $\mathrm{n}^{\circ} 10.639$, de 9 de janeiro de 2003, que modificou a 
Lei de Diretrizes e Bases da Educação Nacional para determinar que "nos estabelecimentos de ensino fundamental e médio, oficiais e particulares, torna-se obrigatório o ensino sobre História e Cultura Afro-Brasileira". ${ }^{29} \mathrm{Em}$ 2008, a Lei $\mathrm{n}^{\circ} 11.645$ complementou essas novas diretrizes curriculares com a inclusão da obrigatoriedade do ensino de História Indígena. Objetivou-se, com isso, denunciar o caráter eurocêntrico e excludente da educação escolar, que marcou de sobremaneira a constituição e a consolidação da História como disciplina escolar, e, em contraposição, promover a diversidade cultural nos currículos escolares.

$\mathrm{Na}$ área da educação escolar, desde a instituição pelo MEC dos Parâmetros Curriculares Nacionais para o Ensino Fundamental, em 1996, valoriza-se o conhecimento do "patrimônio sociocultural brasileiro" como constitutivo do currículo, associado à concepção de pluralidade cultural e ao reconhecimento da diversidade cultural, representada pelas diversas culturas presentes na formação do Brasil e que contribuíram para a construção da identidade nacional, tal como analisou Rebeca Contijo. ${ }^{30}$ Os aspectos comuns entre os PCNs e o Decreto que estabelece as diretrizes para o registro do patrimônio imaterial no Brasil foram destacados por Martha Abreu, visto que "ambos valorizam a especificidade de cada grupo que compõe o todo social, garantindo-lhes não apenas o reconhecimento das diferenças, mas o direito ao exercício de uma cidadania como grupo singular". ${ }^{31}$

Essas reconfigurações das políticas públicas no campo do patrimônio e na educação escolar no sentido de valorizar a história e a cultura africana, afro-brasileira e indígena são parte de um complexo processo que abrange tensões, conflitos presentes na conjuntura política brasileira do período pós-redemocratização e é imprescindível historicizar e problematizar seus pressupostos conceituais.

O conceito de "pluralidade cultural" associado ao de identidade presente nos Parâmetros Curriculares Nacionais, tal como alertam Martha Abreu e Hebe Mattos, pode induzir ao estabelecimento de um "novo modelo" para a relação cultura-identidade, o modelo "multicultural, formado a partir do somatório das diversas sub-culturas $=$ identidades formadoras da nacionalidade brasileira (afro-brasileira, ítalo-brasileira, polonesa-brasileira, alemã-brasileira etc.)". ${ }^{32}$

Da mesma forma, precisamos discutir os conceitos de "cultura" e "identidade". Por exemplo, nas "Diretrizes Curriculares Nacionais para a Educação das Relações Étnico-raciais e para o Ensino de História e Cultura Afro-brasileira e Africana", estabelecidas pelo Conselho Nacional de Educação para orientar a implementação da Lei $n^{\circ} 10.639$, esses conceitos estão explicitamente associados "à demanda da população afrodescendente no sentido políticas de ações afirmativas, isto é, de políticas de reparações, e de reconhecimento e valorização de sua história, cultura, identidade". ${ }^{33}$ Em outras palavras, é necessário criticar a naturalização de determinados grupos culturais 
promovida por concepções que transformam a cultura, a identidade e a memória dos afrodescendentes em conceitos fixos e imutáveis, descontextualizados do processo histórico em que foram construídos. Em contrapartida, compartilhamos do esforço de compreender "essas categorias como politicamente construídas ao longo da história por sujeitos e movimentos sociais que os trouxeram à tona (ou os recriaram) e os elegeram como fundamentais". ${ }^{34}$

Essa discussão deve acompanhar a inclusão das temáticas africanas e afro-brasileiras nos currículos escolares. Tal como estudiosos do campo do currículo alertam, não podemos compreender a educação étnico-racial e o currículo multicultural como o simples acréscimo de conteúdos associados a culturas e identidades que desejamos positivar. A seleção e as formas de abordagem da história e das práticas culturais dos afrodescendentes exigem reflexões que evitem transformar, por exemplo, as práticas culturais afrobrasileiras como a capoeira, o candomblé, as Congadas e as Folias de Reis em unidades didáticas isoladas que configuram "currículos turísticos", na expressão cunhada por Jurjo Santomé, destinados a estudar esporadicamente a diversidade cultural recorrendo a "trivialização", a "estereotipagem", "como souvenir", desconectadas das "situações de diversidade da vida cotidiana nas salas de aula", ou ainda, com formas diversas de "tergiversação", dentre as quais o autor destaca a "psicologização dos problemas raciais e sociais". ${ }^{35}$

Na História escolar, portanto, a abordagem da diáspora africana não deve constituir inserções isoladas de conteúdos - tais como "História da África", "Tráfico Negreiro", "Escravidão nas Américas", "Escravidão no Brasil", caracterizar-se por esparsas menções aos afrodescendentes no pós-abolição ou ainda pelo estabelecimento de relações anacrônicas com o presente na tentativa de tratar da "situação do negro na sociedade brasileira atual".

Verificam-se alterações no tratamento dessas temáticas na literatura didática induzidas pelo "Programa Nacional do Livro Didático" (PNLD), que aponta como um dos "Critérios eliminatórios comuns a todas as áreas", cujo descumprimento significa a exclusão da coleção do Guia de Livros Didáticos do PNLD, a observância das Leis $\mathrm{n}^{0} 10.639 / 2003$ e $\mathrm{n}^{0} 11.645 / 2008$. No Edital do PNLD 2013, por exemplo, os "Princípios Gerais" prescrevem que as propostas pedagógicas das coleções devem colaborar para a construção da cidadania, valorizando o "caráter multicultural de nossa sociedade", ao promover positivamente a imagem e a cultura de afro-descendentes e dos povos indígenas, "considerando seus direitos e sua participação em diferentes processos históricos que marcaram a construção do Brasil". ${ }^{36}$

Em relação aos livros didáticos de História, o tratamento da história dos africanos, afrodescendentes e povos indígenas constitui importante critério de avaliação, observando-se aspectos como "a distribuição dos conteúdos correlatos na obra; a articulação com a abordagem histórica adotada; as relações estabelecidas entre passado-presente".${ }^{37}$ A partir da análise do conjunto 
das obras inscritas em cada uma das edições do PNLD, delineada nos textos introdutórios dos Guias de Livro Didático do PNLD, são apontadas alterações mais significativas na abordagem da história da África e dos africanos e afrodescendentes no Brasil, enquanto que permanecem muitos problemas na inserção da História Indígena nas obras didáticas. No "Guia do PNLD 2013", entre os aspectos positivos destacam-se a explicitação da diversidade de povos que compõe o continente africano, a incorporação da história social sobre a escravidão em parte significativa das obras e a tendência à inserção contínua da História da África e dos afrodescendentes ao longo das coleções. Entretanto, alerta-se que "os avanços identificados não se configuram de forma homogênea no conjunto das obras. Enquanto o novo se anuncia e até mesmo se consolida, elementos de permanência ainda se fazem sentir". ${ }^{38}$ Em especial sobre os livros de História Regional destinados ao $4^{\circ}$ e $5^{\circ}$ anos do Ensino Fundamental, afirma-se que na maioria das obras "a partir da abolição os afro-brasileiros desaparecem das páginas do livro". ${ }^{39}$

Múltiplas indagações são geradas diante desse conjunto de questões: como o conteúdo sobre a história dos africanos e afrodescendentes pode contribuir para novas abordagens da história local nos currículos escolares? O acesso ao website "Santa Afro Catarina" fornece recursos para que os professores possam realizar a mediação didática entre a produção historiográfica sobre a escravidão e o pós-emancipação de forma a abordar essas temáticas nas salas de aula da Educação Básica? Quais estratégias didáticas e metodologias podemos sugerir para que o "Acervo" de documentos históricos seja agenciado na produção de materiais didáticos? Como os recursos disponíveis no site podem suscitar a criação de propostas de Educação Patrimonial integradas ao estudo da história local nas escolas? Quais as múltiplas situações didáticas poderão ser mobilizadas pelo(a)s professore(a)s ao trabalhar com os "Roteiros Históricos" no Ensino Fundamental, no Ensino Médio e na Educação de Jovens e Adultos?

Partimos da premissa que não se trata de promover a "transposição didática", proposta por Yves Chevallard.$^{40}$ Ou seja, não consideramos que a demanda é incorporar nos currículos escolares a renovação historiográfica sobre a presença de africanos e afrodescendentes em Santa Catarina, didatizando ou adaptando o "saber acadêmico" de modo a ser compreendido pelos alunos. Embora esse autor tenha contribuído para apontar o conjunto de agentes, instituições e interesses que determinam o "saber a ser ensinado" - aquele selecionado para compor os currículos - e também tenha colaborado para a compreensão das especificidades do "saber ensinado" nas escolas ao ressaltar a construção didática dessas saberes, concordamos com as críticas que apontam as limitações de suas proposições, visto que Chevallard aponta o saber acadêmico como a única referência ou fonte para a estruturação e transformações dos saberes escolarizados, desconsiderando a dinâmica própria de construção das disciplinas escolares. 
Em consonância com um conjunto de autores e autoras ${ }^{41}$, consideramos que as disciplinas escolares têm um estatuto espefícico e que a escolarização dos saberes deve ser investigada a partir da cultura escolar e das funções desempenhadas pela instituição escolar em diferentes períodos e sociedades. Operamos, assim, com a concepção de "saber escolar", tal exposto por Ana Maria Monteiro:

\begin{abstract}
A categoria "saber escolar" foi utilizada aqui como aquela que designa um conhecimento com configuração cognitiva própria, relacionado mas diferentes do saber científico de referência, e que é criado a partir das necessidades e injunções do processo educativo, envolvendo questões relativas à transposição didática e às medições entre conhecimento científico e conhecimento cotidiano, bem como às dimensões histórica e sociocultural numa perspectiva pluralista. ${ }^{42}$
\end{abstract}

A noção de "mediação didática", na acepção de Alice Cassimiro Lopes ${ }^{43}$, auxilia na compreensão do trabalho de (re)construção de saberes promovido pelos professores que, durante a prática pedagógica, didatizam o conhecimento acadêmico de forma articulada com as práticas sociais dos alunos e o contexto sociopolítico cultural.

A apreensão dos complexos mecanismos de produção do conhecimento histórico escolar constitui, portanto, um dos desafio do campo de pesquisa do ensino da História, com o qual estabelecemos interlocução constante para a produção do conjunto de projetos que compõem a seção "Na Escola", do website "Santa Afro Catarina".

Como o auxílio de bolsistas da graduação, produzimos um conjunto de atividades que agenciam os documentos do "Acervo" e promovem a leitura dos "Temas", algumas vezes complementadas por textos de outros autores. Com isso, seja ao acessar os "Temas" e encontrar atividades que exploram os documentos correlacionados ou ainda ao navegar pelo "Acervo" e se deparar com várias atividades para cada tipo de documento, os professores serão instigados a analisar essas proposições e quem sabe se apropriar desses recursos para criar situações de aprendizagem em sala de aula.

Essas atividades consituem materiais didáticos, ou seja, de acordo com Circe Bittencout são "mediadores do processo de aquisição de conhecimento, bem como facilitadores da apreensão de conceitos, do domínio de informações e de uma linguagem específica da área de cada disciplina - no nosso caso da História". ${ }^{44}$ Ao priorizar o trabalho com fontes históricas na produção de materiais didáticos expressamos determinada compreensão do processo de construção do conhecimento histórico escolar, dos objetivos e da metodologia do ensino de História. 
Na reconfiguração da História como disciplina escolar no período pósditadura militar e, mais especificamente, durante as reformas educacionais promovidas nos anos 1990, a discussão acerca do uso de documentos históricos para o ensino da História foi recorrente. De forma significativa, esteve presente nos Parâmetros Curriculares Nacionais destinados aos Anos Iniciais ${ }^{45}$ e aos Anos Finais do Ensino Fundamental. ${ }^{46}$

A partir da discussão acerca da aproximação da história ensinada em relação ao conhecimento histórico, os PCNs abordam a ampliação da noção de fontes documentais e a "a distinção entre a realidade e a representação da realidade expressa nas gravuras, desenhos, gráficos, mapas, pinturas, esculturas, fotografias, filmes e discursos orais e escritos". ${ }^{47}$ Nas "Orientações e Métodos Didáticos”, várias situações didáticas a serem privilegiadas mencionam procedimentos associados a documentos históricos: "trabalhar documentos variados", "confrontar dados e abordagens", "ensinar procedimentos de pesquisa $[. .$.$] como obter informações em documentos". { }^{48}$ No item "Trabalho com documentos", destaca-se a importância das fontes históricas na produção do conhecimento histórico e historiciza-se a noção de documentos e as abordagens metodológicas, prescrevendo a aproximação das situações didáticas de ensino de História com os procedimentos do ofício do historiador:

Utilizar documentos históricos na sala de aula requer do professor conhecer e distinguir algumas abordagens e tratamentos dados às fontes por estudiosos da História. Requer dele a preocupação de recriar, avaliar e reconstruir metodologias do saber histórico para situações de ensino e aprendizagem. ${ }^{49}$

Em outra política pública iniciada nos anos 1990, a "Avaliação Pedagógica" de obras didáticas como parte do "Programa Nacional do Livro Didático", a questão do uso de documentos constituiu critério importante na Área de História, tal como prescrito em todos os Editais do PNLD, desde a primeira avaliação dos livros didáticos destinados aos Anos Finais do Ensino Fundamental - no PNLD 1999. Enfatiza-se, tal como exemplificado pela citação do Edital do PNLD 2014, que o trabalho com fontes históricas deve estar associado ao objetivo de "viabilizar o pensar historicamente" e possibilitar a compreensão "da História como área de conhecimento":

É fundamental a diferenciação entre a vivência desses processos e a forma de produção de conhecimento sobre eles, ou seja, a compreensão do processo histórico e da produção de conhecimento sobre o mesmo. Da capacidade de perceber claramente essas duas dimensões da História dependerá o reconhecimento do valor do conhecimento 
histórico como base para a compreensão do passado e dos modos humanos padronizados de agir, pensar e sentir, estabelecidos em diferentes tempos e espaços. ${ }^{50}$

A ênfase acerca da importância de se trabalhar com documentos históricos para introduzir procedimentos próprios da construção do conhecimento histórico no ensino da História presente nessas políticas públicas está em consonância com a produção teórica no campo do ensino de História, que aponta a incorporação da compreensão do ofício do historiador e do processo de produção do discurso histórico como objeto privilegiado da História como disciplina escolar. ${ }^{51}$

Dentre muitos usos possíveis das fontes históricas em sala de aula, nos interessa sobremaneira aqueles que se identificam com a proposição de agenciar documentos históricos para "mostrar às novas gerações a natureza $\mathrm{e}$ a especificidade do conhecimento histórico" e "ensinar como os historiadores produzem conhecimento sobre o passado a partir das fontes disponíveis e quais os procedimentos implicados nessa produção". ${ }^{22} \mathrm{O}$ professor torna-se, portanto, um provocador de situações de aprendizagens que mobilizam o trabalho com uma gama variada de documentos a fim de promover o desenvolvimento de operações cognitivas, noções e conceitos próprios da História como área de conhecimento.

A partir dessa premissa, os referenciais da epistemologia da história orientaram a metodologia de interpretação e análise dos documentos históricos configurada no "Roteiro de Trabalho com documentos históricos em sala de aula", elaborado para auxiliar os alunos de graduação na produção de atividades que agenciam procedimentos de interpretação e análise de fontes históricas do "Acervo", explorando-as e contextualizando-as a partir das condições e circunstâncias históricas de sua produção.

Essa compreensão teórica e metodológica acerca do ensino de História também orientou o Estágio Supervisionado em História realizado no âmbito do "Santa Afro Catarina", quando oito alunos desenvolveram o projeto "Educação Patrimonial e História Local: os africanos e afrodescendentes na Ilha de Santa Catarina", na Escola Básica Municipal Dilma Lúcia dos Santos, localizada no bairro da Armação do Pântano do Sul, em Florianópolis.

Fundamentados na "História Temática" que propõe a abordagem dos conteúdos associada a eixos temáticos e ao estudo de múltiplas temporalidades, cada dupla de estagiários, a partir da investigação sobre o bairro da Armação no passado e no presente, estabeleceu uma temática associada ao campo do patrimônio - alimentação, trabalho, meio ambiente e práticas culturais - e a problematizou para a construção de diferentes projetos de educação patrimonial.

A fim de trabalhar cada uma das temáticas de forma a promover a abordagem interrelacionada das experiências dos homens e mulheres africanos e afrodescendentes e das práticas culturais associadas ao patrimônio, os 
estagiários produziram os materiais didáticos que utilizaram durante a prática pedagógica no Estágio Supervisionado, com base no estudo da historiografia e da incorporação dos "Temas" e do "Acervo" do Programa "Santa Afro Catarina".

Para agenciar os conhecimentos prévios dos alunos e suas experiências sociais, cada dupla de estagiários planejou "Roteiros" para orientar as pesquisas que foram realizadas pelos estudantes da Escola Dilma Lúcia dos Santos na comunidade da Praia da Armação, a fim de investigar temas associados às práticas socioculturais que representam a trajetória histórica do bairro e, assim, estimular a reflexão sobre a memória e o patrimônio cultural.

Essa proposta de educação patrimonial visa, assim, associar o estágio supervisionado ao ensino da história local, explorando as potencialidades dessa estratégia pedagógica, apontadas por Maria Auxiliadora Schmidt em vários trabalhos $^{53}$ : produzir a inserção do aluno na comunidade da qual faz parte por meio da prática de coleta de documentos e da história oral, de modo que ele identifique como se constituiu e se desenvolveu uma historicidade própria a esse lugar, necessariamente associada ao contexto histórico nacional e internacional.

No "Na Escola", na seção "Experiências", os internautas encontrarão os quatro Relatórios de Estágio, com os projetos de ensino que orientaram a prática pedagógica, os materiais didáticos produzidos e as reflexões sobre o currículo em ação, ou seja, sobre o cotidiano de desenvolvimento das aulas. ${ }^{54}$

Em consonância com as práticas de compartilhamento que a internet possibilita e instiga, nossa intenção é que o website "Santa Afro Catarina" seja apropriado de múltiplas formas por um público variado. Por isso, um espaço será reservado para receber comentários e contribuições. Em especial, desejamos que o "Na Escola" possa constituir um espaço de diálogo com os professores e professoras da Educação Básica e de divulgação de experiências de agenciamentos múltiplos dos "Temas", do "Acervo", dos "Roteiros" e das "Atividades" em práticas pedagógicas e de Educação Patrimonial.

Nosso intuito é o de promover, por diferentes estratégias, a associação entre as experiências históricas inscritas em temporalidades diversas e o espaço da Ilha de Santa Catarina. Eventos, incidentes e episódios do dia-a-dia acontecem em lugares de convivência, de trabalho e de moradia do núcleo urbano de Desterro e nas freguesias - atuais distritos da cidade de Florianópolis - e são exemplares das trajetórias individuais e coletivas dos africanos e seus descendentes, durante a escravidão ou depois da abolição, representando a luta pela sobrevivência e pela autonomia, a defesa dos direitos, os laços de solidariedade, as práticas culturais e de resistência à opressão e ao preconceito.

Pretendemos, assim, que estudantes, professores, pessoas interessadas na história, turistas possam se apropriar do website "Santa Afro Catarina" de forma a torná-lo uma ferramenta que contribua para a aprendizagem histórica que, na acepção de Rüsen, "traz à tona um aumento da experiência do passado 
humano, tanto como um aumento da competência histórica que dá significado a esta experiência, e na capacidade de aplicar estes significados históricos aos quadros de orientação na vida prática". ${ }^{55}$ Por isso, menos do que divulgar o conhecimento histórico sobre a escravidão e o pós-emancipação, nos interessa que os recursos disponíveis no site sejam mobilizados pelos internautas na construção de novos olhares e experiências em relação à Ilha de Santa Catarina e ao patrimônio cultural. 


\section{NOTAS}

${ }^{1} \mathrm{O}$ endereço do website "Santa Afro Catarina" $\mathrm{e}<\mathrm{http}$ ://santaafrocatarina.ufsc.br $>$ (lançamento progressivo dos temas a partir do primeiro semestre de 2015).

${ }^{2}$ UNIVERSIDADE FEDERAL DE SANTA CATARINA/CURSO DE HISTÓRIA. Projeto Politico Pedagógico do Curso de Graduação em História. Florianópolis, junho de 2006. Disponível em: <http://historia.grad.ufsc.br/files/2012/03/ppp.pdf> . Acesso em: 12 maio 2014.

${ }^{3}$ O Programa "Santa Afro Catarina: Educação Patrimonial e a presença de africanos e afrodescendentes na Ilha de Santa Catarina" é financiado pelo Programa de Extensão Universitária do Ministério da Educação - Edital PROEXT 2011 e Edital PROEXT 2013 e pelo PROCULTURA/UFSC, Edital 2013. Também contou com bolsistas do Programa PROBOLSAS/PROEXT, do Programa Bolsa Permanência/PRAE e de Bolsa Cultura/SeCult da Universidade Federal de Santa Catarina.

${ }^{4}$ A associação entre a açorianidade, o patrimônio cultural e as políticas de turismo foram investigadas nos trabalhos de CARDOSO, Jaqueline Henrique. Políticas de Turismo, Patrimonialização e Tensões Identitárias: Santo Antônio de Lisboa, Florianópolis, SC (19662012). Dissertação (Mestrado em História) - Universidade do Estado de Santa Catarina, Florianópolis, 2013. LEAL, João. Cultura e identidade açoriana: o movimento açorianista em Santa Catarina. Florianópolis: Insular, 2007. SOUSA, Rose Maria Martins Gomes de. Alimentação e culinária na cultura dos descendentes de açorianos em Santo Antônio de Lisboa - Florianópolis (Ilha de Santa Catarina - Brasil). Dissertação (Mestrado) - Universidade de Lisboa, Lisboa, 2010.

${ }^{5}$ CHARTIER, Roger. A história na era digital. In: .A história ou a leitura do tempo. Belo Horizonte: Autêntica, 2009. p. 59-63.

${ }^{6}$ Disponível em: $<\mathrm{http}: / /$ slavevoyages.org/>. Compilado por equipe coordenada por David Eltis e financiado, entre outros, pelo National Endowment for the Humanities (EUA). Acesso em: 01 jun. 2014.

${ }^{7}$ Disponível em: <http://african-origins.org/>. Compilado por equipe coordenada por David Eltis e financiado, entre outros, pelo National Endowment for the Humanities (EUA). Acesso em: 01 jun. 2014.

${ }^{8}$ Disponível em: $<$ http://www.vanderbilt.edu/esss/>. Compilado por equipe coordenada por Jane Landers e financiado, entre outros, pelo National Endowment for the Humanities (EUA) e pelo Fundo para Arquivos Ameaçados da British Library. Acesso em: 01 jun. 2014.

${ }^{9}$ Disponível em: <www.slaveryimages.org $>$. Acervo reunido por Jerome Handler e Michael Tuite, com o financiamento da Virginia Foundation for the Humanities e da Biblioteca da University of Virginia. Acesso em: 01 jun. 2014.

${ }^{10}$ Disponível em: <http://www.ifch.unicamp.br/cecult/lex/web/>. Acervo reunido por equipe coordenada pela professora Silvia H. Lara, em colaboração com Cristina Nogueira da Silva, da Universidade Nova de Lisboa. Acesso em: 01 jun. 2014.

${ }^{11}$ Disponível em: <http://www.ifch.unicamp.br/cecult/lex/web/>. Acervo reunido por equipe coordenada pela professora Silvia H. Lara, em colaboração com Cristina Nogueira da Silva, da Universidade Nova de Lisboa. Acesso em: 01 jun. 2014.

${ }^{12}$ Disponível em: <http://www.labhoi.uff.br/escravidao>. Acesso em: 01 jun. 2014.

${ }^{13}$ Disponível em: $<\mathrm{http}: / /$ slavevoyages.org/tast/education/lesson-plans.faces $>$. Acesso em: 01 jun. 2014. 
${ }^{14}$ CHARTIER, op. cit., p. 59.

${ }^{15}$ NORA, Pierre. Entre memória e história. A problemática dos lugares. Projeto História. São Paulo, n. 10, p. 7-28, 1993.

${ }^{16}$ Os documentos foram coletados durante o desenvolvimento dos projetos de pesquisa dos professores Beatriz Gallotti Mamigonian e Henrique Espada Lima e de seus orientandos e orientandas, que elaboraram Trabalhos de Conclusão de Curso, dissertações de Mestrado e teses de Doutorado sobre a temática da escravidão e do pós-emancipação.

${ }^{17}$ A narrativa temática sobre a Armação Baleeira de Nossa Senhora da Piedade foi nossa primeira incursão fora dos limites da Ilha de Santa Catarina. Pretendemos abordar temas relativos a outros locais catarinenses, uma vez que a presença de africanos e descendentes de africanos foi significativa em todo o litoral e também no planalto catarinense.

${ }^{18}$ REVEL, Jacques (Org.). Jogos de escala. A experiência da microanálise. Rio de Janeiro: Fundação Getúlio Vargas, 1998.

${ }^{19}$ MAMIGONIAN, Beatriz; VIDAL, Joseane. Uma história diversa de Florianópolis. In: (Orgs.). História diversa: africanos e afrodescendentes na Ilha de Santa Catarina. Florianópolis: Editora da UFSC, 2013.

${ }^{20}$ FARGE, Arlete. O sabor do arquivo. São Paulo: Editora da Universidade de São Paulo, 2009. p. 14.

${ }^{21}$ Ibidem, p. 15.

${ }^{22}$ Ibidem, p. 70.

${ }^{23}$ Ibidem, p. 93-94.

${ }^{24}$ Verbete do website "Santa Afro Catarina".

${ }^{25}$ LEITE, Ilka Boaventura (Org.). Negros no sul do Brasil: invisibilidade e territorialidade. Ilha de Santa Catarina: Letras Contemporâneas, 1996. MAMIGONIAN, Beatriz G. Africanos em Santa Catarina: escravidão e identidade étnica (1750-1850). In: FRAGOSO, João Luis Ribeiro; FLORENTINO, Manolo G.; SAMPAIO, Antonio Carlos Jucá; CAMPOS, Adriana. (Orgs.). Nas rotas do Império: eixos mercantis, tráfico e relações sociais no mundo português. Vitória; Lisboa; Brasília: Ed. UFES; Instituto de Investigações Científicas Tropicais; CNPq, 2006. p. 609-644.

${ }^{26}$ A trajetória do IPHAN é objeto de estudo de muitos trabalhos, entre eles: CHUVA, Márcia. Os arquitetos da memória: sociogênese das práticas de preservação do patrimônio cultural no Brasil (anos 1930-1940). Rio de Janeiro: Ed. da UFRJ, 2009; FONSECA, Maria Cecília Londres. O Patrimônio em processo: trajetória da política federal de preservação no Brasil. Rio de Janeiro: Editora UFRJ/MINC/IPHAN,1997; GONÇALVES, José Reginaldo. A retórica da perda: os discursos do patrimônio cultural no Brasil. Rio de Janeiro: Editora da Uerj 1996; SANTOS, Marisa Veloso. O tecido do tempo: a ideia de patrimônio cultural no Brasil (1920-1970). Tese (Doutorado em Antropologia) - Universidade de Brasília, Brasília, 1992; RUBINO, Silvana. O mapa do Brasil passado. Revista do Patrimônio Histórico e Artístico Nacional. Brasília, n. 24, p. 97-105, 1996.

${ }^{27}$ COSTA, Flávia Roberta. Turismo e patrimônio cultural: interpretação e qualificação. São Paulo: Editora SENAC / Edições SESC-SP, 2009.

${ }^{28}$ MENESES, José Newton Coelho. História \& Turismo Cultural. Belo Horizonte: Autêntica, 2004. p. 57.

${ }^{29}$ BRASIL, Lei n ${ }^{\circ} 10.639$, de 9 de janeiro de 2003. 
${ }^{30}$ CONTIJO, Rebeca. Identidade nacional e ensino de História: a diversidade como patrimônio sociocultural. In: ABREU, Martha; SOHIET, Raquel (Orgs.). Ensino de História: conceitos, temáticas e metodologias. Rio de Janeiro: Casa da Palavra, 2003. p. 55-79.

${ }^{31}$ ABREU, Martha. Cultura imaterial e patrimônio histórico nacional. In: ABREU, Matha; SOIHET, Rachel; GONTIJO, Rebeca (Orgs.). Cultura politica e leituras do passado: historiografia e ensino de história. Rio de Janeiro: Civilização Brasileira, 2007. p. 364.

32 ABREU, Martha; MATTOS, Hebe. Em torno das "Diretrizes curriculares nacionais para a educação das relações étnico-raciais e para o ensino de história e cultura afro-brasileira e africana": uma conversa com historiadores. Estudos históricos. Rio de Janeiro, v. 21, n. 41, p. 8 , jan./jun. 2008.

${ }^{33}$ BRASIL, CONSELHO NACIONAL DE EDUCAÇÃO/MEC. Diretrizes Curriculares Nacionais para a Educação das Relações Étnico-raciais e para o Ensino de História e Cultura Afro-brasileira e Africana. Brasília: 2004. p. 2.

${ }^{34}$ ABREU; MATTOS, op. cit., p. 12.

${ }^{35}$ SANTOMÉ, Jurjo T. As culturas negadas e silenciadas no currículo. In: SILVA, Tomaz Tadeu (Org.). Alienígenas na sala de aula - Uma introdução aos estudos culturais em educação. Petrópolis, RJ: Vozes, 1995. p. 159-177.

${ }^{36}$ BRASIL/Ministério da Educação. Edital de convocação para o processo de inscrição e avaliação de coleções didáticas para o Programa Nacional do Livro Didático - PNLD 2013, p. 27.

${ }^{37}$ BRASIL/Secretaria de Educação Fundamental. Guia de Livros Didáticos PNLD 2012 História. Brasília: Ministério da Educação, 2011, p. 21.

${ }^{38}$ BRASIL/Secretaria de Educação Fundamental. Guia de Livros Didáticos PNLD 2013 História. Brasília: Ministério da Educação, 2012, p. 25.

${ }^{39}$ Idem.

${ }^{40}$ CHEVALLARD, Yves. La transposición didáctica. Del saber sabio al saber enseñado. Buenos Aires: Aique Grupo Editor, 2005.

${ }^{41}$ CHERVEL, André. História das disciplinas escolares: reflexões sobre um campo de pesquisa. Teoria \& Educação. Porto Alegre, n. 2, p. 177-229, 1990. FORQUIN Jean-Claude. Escola e cultura. As bases epistemológicas do conhecimento escolar. Porto Alegre: Artes Médicas, 1993. GABRIEL, Camen Teresa. O conceito de história-ensinada: entre a razão pedagógica e a razão histórica. Reflexões sobre a natureza epistemológica do saber histórico escolar. In: CANDAU, Vera Maria (Org.). Reinventar a escola. Petrópolis, RJ: Vozes, 2000. p. 238-259. MONTEIRO, Ana Maria. Professores de História: entre saberes e práticas. Rio de Janeiro: Mauad X, 2007.

42 MONTEIRO, Ana Maria. A história ensinada: algumas configurações do saber escolar. História \& Ensino. Londrina, v. 9, p. 14, out. 2003.

${ }^{43}$ LOPES, Alice Casimiro. Conhecimento escolar: processos de seleção cultural e de mediação didática. Educação \& Realidade. Porto Alegre, n. 22, p. 95-111, jan./jun. 1997.

${ }^{44}$ BITTENCOURT, Circe M. Fernandes. Ensino de história: fundamentos e métodos. São Paulo: Cortez, 2004. p. 296.

${ }^{45}$ BRASIL/Secretaria de Educação Fundamental. Parâmetros Curriculares Nacionais para o Primeiro e Segundo Ciclos: História e Geografia. Brasília: Ministério da Educação, 1996. 
${ }^{46}$ BRASIL/Secretaria de Educação Fundamental. Parâmetros Curriculares Nacionais $5^{a} a 8^{a}$ Séries. Brasília: Ministério da Educação, 1998.

${ }^{47}$ Ibidem, p. 32.

${ }^{48}$ Ibidem, p. 77.

${ }^{49}$ Ibidem, p. 83.

${ }^{50}$ BRASIL/Ministério da Educação. Edital de convocação para o processo de inscrição e avaliação de coleçães didáticas para o Programa Nacional do Livro Didático - PNLD 2014, p. 58. Disponível em: $<$ http://www.fnde.gov.br/programas/livro-didatico/livro-didatico-editais/ item/3963-pnld-2014-anos-finais-do-ensino-fundamental>. Acesso em: 12 maio 2014.

${ }^{51}$ Ver, entre outros, BITTENCOURT, Circe M. Fernandes. Ensino de história: fundamentos e métodos. São Paulo: Cortez, 2004. CAIMI, Flávia Eloisa. Fontes históricas na sala de aula: uma possibilidade de produção do conhecimento histórico escolar? Anos 90. Porto Alegre, v. 15, n. 28, p. 129-150, dez. 2008. MIRANDA, Sônia. O que significa educar para a compreensão histórica? Um olhar a partir de um programa de avaliação educacional. História \& Ensino. Londrina, v. 9, p. 301-319, out. 2003. SCHMIDT, Maria Auxiliadora, CAINELLI, Marlene. Ensinar História. São Paulo: Scipione, 2009.

${ }^{52}$ PEREIRA, Nilton; SEFFNER, Fernando. O que pode o ensino de história? Sobre o uso de fontes na sala de aula. Anos 90. Porto Alegre, v. 15, n. 28, p. 126-127, dez. 2008.

${ }^{53}$ SCHMIDT, Maria Auxiliadora. O ensino de história local e os desafios da formação da consciência histórica. In: MONTEIRO, Ana Maria; GASPARELLO, Arlette Medeiros; MAGALHÃES, Marcelo de Souza (Orgs.). Ensino de História: sujeitos, saberes e práticas. Rio de Janeiro: Mauad X, FAPERJ, 2007. p. 187-198. SCHMIDT, Maria Auxiliadora; GARCIA, Tania Braga. A formação da consciência história de alunos e professores e o cotidiano em aulas de história. Cadernos Cedes, v. 25, n. 67, p. 297-308, set./dez. 2005.

${ }^{54}$ GOULART, Mariana. Ensino de História e a alimentação como prática cultural: um diálogo possível. Relatório de Estágio. Curso de História. Universidade Federal de Santa Catarina. Florianópolis, 2013. RODRIGUES, Icles; ANDRADE, Rodrigo. Entre o conhecer e o reconhecer: educação patrimonial e o saber-fazer de pescadores na Armação do Pântano do Sul. Relatório de Estágio. Curso de História. Universidade Federal de Santa Catarina. Florianópolis, 2013; SCHVEITZER, Ana Carolina. História local e patrimônio ambiental: a Praia da Armação como um espaço de mémoria, ensino e experiência. Relatório de Estágio. Curso de História. Universidade Federal de Santa Catarina. Florianópolis, 2013; SOUZA, Isabella C., GONDIM, Letícia. O boi-de-mamão e as festas de africanos e afrodescendentes: uma experiência de educação patrimonial no ensino de História. Relatório de Estágio. Curso de História. Universidade Federal de Santa Catarina. Florianópolis, 2013.

${ }^{55}$ RÜSEN, Jörn. Experiência, interpretação, orientação: as três dimensões da aprendizagem histórica. In: SCHIMIDT, Maria Auxiliadora; BARCA, Isabel; MARTINS, Estevão (Orgs.). Jörn Rüsen e o ensino de História. Curitiba: Ed. UFPR, 2010. p. 84.

\section{Artigo recebido em junho de 2014. Aceito em agosto de 2014.}

